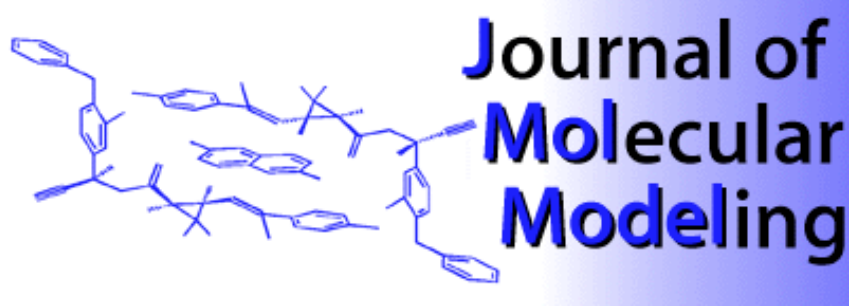

Full Paper

(C) Springer-Verlag 2000

\title{
The Interplay of Angle Strain and Aromaticity: Molecular and Electronic Structures of $\left[0_{n}\right]$ Paracyclophanes
}

\author{
Mavinahalli N. Jagadeesh¹, Anindita Makur², and Jayaraman Chandrasekhar ${ }^{1,2}$ \\ ${ }^{1}$ Department of Organic Chemistry, Indian Institute of Science, Bangalore 560 012, India. Tel.: 91-80-3092578; \\ Fax: 91-80-360 0529. E-mail: chandru@master.chem.yale.edu \\ ${ }^{2}$ Jawaharlal Nehru Centre for Advanced Scientific Research, Jakkur P.O., Bangalore 560064, India
}

Received: 25 October 1999/ Accepted: 14 Janaury 2000/ Published: 28 February 2000

\begin{abstract}
The belt-like polyphenylenes, [0 $\left.{ }_{n}\right]$ paracyclophanes, $(n=5$ and 6$)$, have been investigated using semi-empirical, $a b$ initio and DFT methods. The molecular structure, rotational barrier on twisting a single phenyl ring and the aromatic character within each ring as well as in the whole molecule have been evaluated. $\left[0_{5}\right]$ Paracyclophane is predicted to have a quinonoid structure. In contrast, the equatorial pentaphenyl fragment found in $\mathrm{C}_{70}$ as well as the hexagons of the less strained $\left[0_{6}\right]$ paracyclophane have benzenoid character. Approximate band structures have been derived for larger cycles of $\left[0_{n}\right]$ paracyclophanes.
\end{abstract}

Keywords Strained rings, Aromaticity, Ab initio, AM1, MNDO, B3LYP

\section{Introduction}

The discovery of fullerenes [1] and subsequent characterization of carbon nanotubes [2] have generated an upsurge of interest in conjugated systems with a curved surface [3]. Several beautiful arrangements of carbon atoms as cage structures and as their fragments, such as bowls and belts, have caught the imagination of synthetic chemists [4]. Particularly noteworthy are the highly symmetrical belt-shaped compounds primarily constructed using hexagons, such as $\left[0_{n}\right]$ paracyclophanes $(\mathbf{1 a}, \mathrm{n}=5 ; \mathbf{1 b}, \mathrm{n}=6)[5],\left[\mathrm{m}_{\mathrm{n}}\right]$ paraphenyl-

Correspondence to: J. Chandrasekhar

Dedicated to Professor Paul von Ragué Schleyer on the occasion of his $70^{\text {th }}$ birthday n-acetylenes $(2, \mathrm{n}=6)$ [6], [n]cyclacene $(3, \mathrm{n}=6)$ [7], and $\pi$-spherands $(\mathbf{4 a}, \mathrm{n}=2 ; \mathbf{4 b}, \mathrm{n}=3$ ) [8] (Scheme 1). They are of interest not only from synthetic and theoretical points of view but also as host molecules having a rigid cavity lined with $\pi$ bonds. Some of these molecules may have unusual and useful properties, which could lead to applications such as providing a vehicle for delivering drugs, artificial cell membranes, molecular sieves and molecular electronic devices [9].

Among the belt shaped molecules 1-4, the class of $\left[0_{n}\right]$ paracyclophanes represent an important conceptual link between planar graphitic sheets and spheroidal fullerenes [10]. While graphite is the prototypical aromatic system, different rings of fullerenes exhibit varying degrees of conjugation [11], often attributed to the disrupting influence of the pentagons necessarily present in these molecules. In 1, conjugation occurs over a curved surface, but without the distracting influence of pentagons. It is therefore useful to 
examine how the $\pi$ system in a belt-like topology responds to varying degrees of strain.

The relation between fullerenes and belt- or tube-shaped molecules becomes clear by considering the fully characterized molecular structures of fullerenes. For example, the structure of $\mathrm{C}_{70}$ can be viewed as two corannulene units held together by a belt of five phenyl units (Figure 1). This description accounts for the bond length variation found in $\mathrm{C}_{70}$ and also provides the basis for understanding the reactive sites in $\mathrm{C}_{70}$ as well as relative stabilities of addition products [12]. The belt-shaped subunit with five phenyl units joined in parapara positions is $\left[0_{5}\right.$ ]paracyclophane. Larger analogs form the building blocks of carbon nano-tubes.

Experimentally, relatively little is known of the molecular and electronic structures of [ $\left.0_{n}\right]$ paracyclophanes, although Guha et al. attempted to synthesize the derivatives corresponding to $\mathrm{n}=3-6$, as far back as in 1934 [13]. Recently, Tsuji et al. were successful in generating and trapping tricyclo[4.2.2.2 2,5$]$ dodeca-1,3,5,7,9,11-hexaene, $\mathbf{5}$, which is the smallest representative in [ $0_{n}$ ]paracyclophane, with $n=2$ [14]. The tetrabenzo derivative tetradehydrodianthracene (TDDA), 6 , is a more stable compound closely related to $\mathbf{5}$. Viavattene et al. successfully synthesized $\mathbf{6}$ and determined its structure through X-ray diffraction [15]. The central hexagons do not have benzenoid character as in $\mathbf{5} \mathbf{b}$. The connecting links are essentially double bonds as in $\mathbf{5 a}$. Thus, the molecule is a fully unsaturated variant of tricyclo-[4.2.2.2 $2^{2,5}$ dodeca-1,5diene, $\mathbf{4 a}$, the $\pi$-spherand with $\mathrm{n}=2$. The observed bond localization can readily be attributed to the preferred benzenoid character of the outer hexagons of the two anthracene units. Recently, Kammermeier et al. showed that $\mathbf{6}$ is very useful in the synthesis of pico-tubes $\left(\left[0_{4}\right]\right.$ paracyclophanes) by ring expansion and metathesis process [16]. The outer benzo units would again force bond localization around the belt. The structure of $\left[0_{10}\right]$ paracyclophane, one of the higher analogues of $\left[0_{n}\right]$ paracyclophane 1 , has been considered and synthesis of this molecule as well as other members of the series with $n=6-10$ have been proposed by Vögtle [5].

Computational methods are particularly suited for the study of these molecules, which suffer from considerable strain. We have examined $\left[0_{5}\right]$ paracyclophane, 1a $(\mathrm{n}=5)$, since it is a fragment of $\mathrm{C}_{70}$ (Figure 1), and its higher analog $\left[0_{6}\right]$ paracyclophane, $\mathbf{1 b}(\mathrm{n}=6)$. We have investigated the electronic structures of the two compounds with $D_{5 h}$ and $D_{6 h}$ symmetry respectively, at various levels of theory. The rotational barrier on twisting a single phenyl ring in $\left[0_{n}\right]$ paracyclophanes and its effect on the electronic structure, the aromatic character of each ring as well as of the whole system are studied. The calculations reveal the intrinsic nature of delocalization around these belts, without any constraints imposed by additional pentagons or benzo fusion. We have also estimated the band gap for infinitely connected paracyclophanes from the two small parent structures using a semiempirical method, by performing limited CI calculations. Approximate band structures were derived for both the compounds at both semiempirical and $a b$ initio methods.

\section{Computational details}

Geometry optimizations were carried out using the semiempirical MNDO and AM1 Hamiltonians [17] and ab initio Hartree-Fock procedure with the split-valence 3-21G basis set [18]. The four structures, $\left[0_{5}\right]-$ and $\left[0_{6}\right]$ paracyclophanes with $D_{5 h}$ and $D_{6 h}$ symmetry and corresponding rotational isomers, obtained by twisting a single phenyl ring in $\left[0_{n}\right]$ paracyclophanes, with $C_{2 v}$ symmetry were considered. Additional computations were also performed at $\mathrm{HF} / 6-31 \mathrm{G}^{*}$ and B3LYP/6-31G* levels [19]. The Nucleus Independent Chemical Shifts (NICS) [20] values were computed for 1a and $\mathbf{1 b}$, at the center of each structure as well as at the center of the six-membered rings using the HF/3-21G method to assess the aromatic nature of the whole system as well as the individual phenyl moieties. Approximate band structures were derived at both AM1 and HF/3-21G levels. The procedure for the derivation of band structure from the calculations on oligomers, proposed by Chandrasekhar and Das [21], is as follows.

It is known that many physical and chemical properties of polymers can be extracted from the theoretical and experimental results on the corresponding oligomers [22]. Band
Figure 1 Two views of the structure of $C_{70}$. Note the saffron colored belt of five hexagons holding together two corannulene skeletons
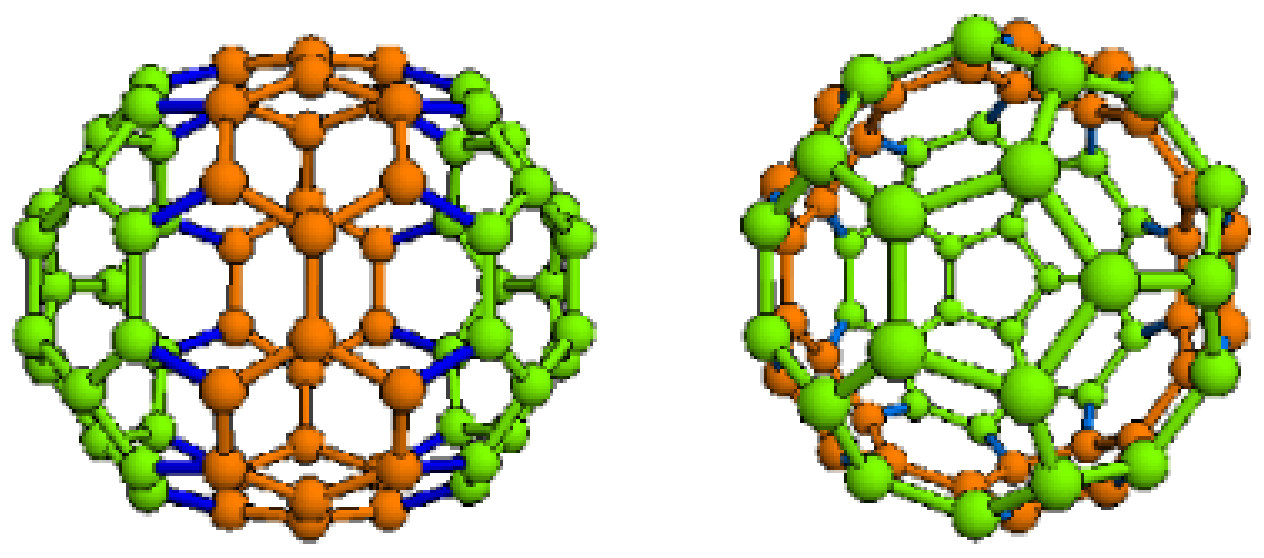
structures of polymers can also be obtained from finite oligomer calculations. Cui et al. [23] suggested a procedure which involves the assignment of $\mathbf{k}$ values of a continuous energy band to each of the discrete orbital energies obtained from oligomer calculations. The procedure was refined by Chandrasekhar and Das [21], who suggested the use of periodic boundary conditions to eliminate some of the problems associated with calculations on oligomers.

In HMO theory, the $\pi$ orbital energies for a ring of $\mathrm{N}$ orbitals are given by:

$\mathrm{E}_{\mathrm{j}}(\operatorname{ring})=\alpha+2 \beta \cos (2 \pi \mathrm{j} / \mathrm{N})$

where $\alpha$ is the coulomb integral, $\beta$ is the resonance integral, and $\mathrm{j}=0, \pm 1, \pm 2, \ldots \mathrm{N} / 2$ for even $\mathrm{N}$ or $\pm \mathrm{N} / 2$ for odd $\mathrm{N}$. The corresponding expression for a linear polyene chain of length $\mathrm{M}$ is:

$\mathrm{E}_{\mathrm{j}}($ linear $)=\alpha+2 \beta \cos (\pi \mathrm{j} /(\mathrm{M}+1))$

The orbital energies of an infinite polymer chain are continuous and vary as $\alpha+2 \beta \cos (\mathbf{k a})$, where a is the separation between successive interacting orbitals (unit cell length in one-dimension). Cui et al. argued that a sufficiently long linear chain can be used as a model for an infinite polymer [23]. They pointed out that the orbital energies of a finite chain are contained in the band structure of the corresponding infinite chain. Each of the discrete molecular orbital energies obtained for the finite chain corresponds to a unique $\mathbf{k}$ vector point on the band structure of the polymer. The $\mathbf{k}$ values for each of the MO's of the oligomer can be obtained by using the following analogy. The orbital energies of the chain are related to those of the ring by choosing the latter in such a way that $\mathrm{N}=2(\mathrm{M}+1)$. Thus, Eq. 1 and Eq. 2 can be combined as follows:

$E_{j}($ ring $)=\alpha+2 \beta \cos (\pi j /(M+1))$

This analogy can be extended to the infinite polymer. Then the orbital energies of the finite chain correspond to $\mathbf{k}$ vector points given by:

$\mathrm{k}_{\mathrm{q}}=\pi \mathrm{q} /(\mathrm{M}+1) \mathrm{a} \quad \mathrm{q}=1,2,3, \ldots \mathrm{M}$

A more direct comparison between the $\mathbf{k}$ vector points of a polymer and the discrete orbital energies of a ring-like oligomer is possible via Eq. 1, leading to the expression:

$\mathrm{k}_{\mathrm{q}}=2 \pi \mathrm{q} / \mathrm{Ma} \quad \mathrm{q}=0, \pm 1, \pm 2, \ldots$

The procedure can be illustrated with a specific example. Polyacetylene may be approximated by a chain containing 5 $\mathrm{C}=\mathrm{C}$ double bonds connected by alternating single bonds and terminated by hydrogen atoms (decapentaene, $M=5$ ). The model would result in $5 \pi$ MO's and $5 \pi^{*}$ MO's, derived from linear combination of $\pi$ and $\pi^{*}$ orbitals on the individual $\mathrm{C}=\mathrm{C}$ units. Each level corresponds to a $\mathbf{k}$ value 1/6, 2/

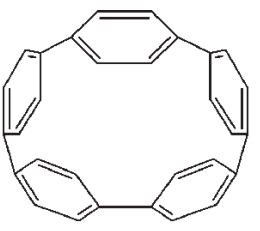

$1 \mathbf{a}$

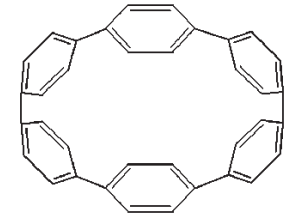

$1 \mathrm{~b}$

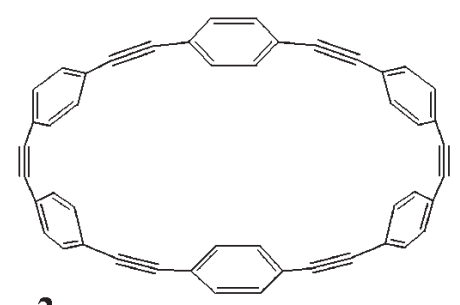

2

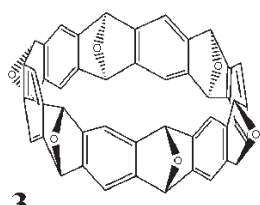

3

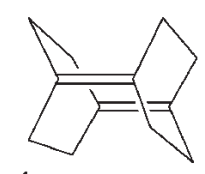

$4 a$

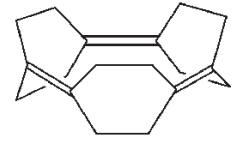

$4 b$

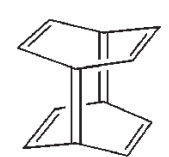

5a

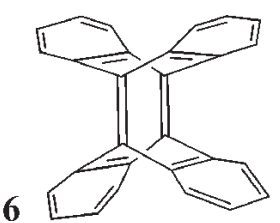

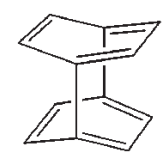

$5 \mathbf{b}$

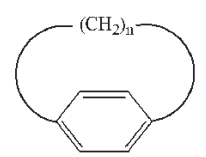

7
Scheme 1 Structures 1 - 7

$6,3 / 6,4 / 6$, and $5 / 6$ in units of $\pi / a$, where a is the separation between successive double bonds. If the same $5 \mathrm{C}=\mathrm{C}$ double bonds are used with periodic boundary conditions and without the terminating hydrogen atoms, one would get orbital energy levels corresponding to $\mathbf{k}$ values of $0, \pm 2 / 5$, and $\pm 4 / 5$.

An important step in the computational procedure, especially in all-electron calculations, is to determine the nature of a molecular orbital and to obtain its $\mathbf{k}$ value. The degree to which a molecular orbital $n$ corresponds to a given $\mathbf{k}$ vector value $q$ can be determined using the expression:

$X_{q}=\sum_{r}\left|\sum_{j} C_{r j}(n) \sin (2 q \pi j / N)\right|$

The computed $\mathrm{X}_{\mathrm{q}}$ is the maximum for a unique $\mathrm{q}$ value for each MO. In practice, the $\mathrm{X}_{\mathrm{q}}$ values are virtually zero for all but one q. The summation $\mathrm{r}$ is over the AO's. 
Table 1 Calculated heats of formation ( $\mathrm{ccal} \mathrm{mol}^{-1}$ ) and total energies (negative Hartree) of $\mathbf{1 a}$ and $\mathbf{1 b}$. Relative energies

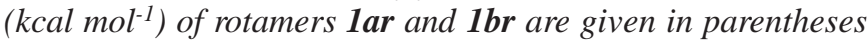

\begin{tabular}{llllll}
\hline $\begin{array}{l}\text { Structure } \\
\text { (Point group) }\end{array}$ & MNDO & AM1 & $\begin{array}{l}\text { HF/3-21G// } \\
\text { HF/3-21G }\end{array}$ & $\begin{array}{l}\text { HF/6-31G*// } \\
\text { HF/3-21G }\end{array}$ & $\begin{array}{l}\text { B3LYP/6-31G*/I } \\
\text { HF/3-21G }\end{array}$ \\
\hline $\mathbf{1 a}\left(D_{5 h}\right)$ & $244.67(0.0)$ & $253.76(0.0)$ & $1141.05172(17.39)$ & $1147.47832(1.51)$ & $1155.01867(19.75)$ \\
$\mathbf{1 a r}\left(C_{2 v}\right)$ & $269.81(25.14)$ & $259.70(5.94)$ & $1141.07944(0.0)$ & $1147.48073(0.0)$ & $1155.05015(0.0)$ \\
$\mathbf{1 b}\left(D_{6 h}\right)$ & $258.12(0.0)$ & $242.19(0.0)$ & $1369.40548(0.0)$ & $1377.10082(0.0)$ & $1386.17313(0.0)$ \\
$\mathbf{1 b r}\left(C_{2 v}\right)$ & $267.65(9.53)$ & $259.24(17.05)$ & $1369.39042(9.45)$ & $1377.07836(14.09)$ & $1386.14619(16.91)$ \\
\hline
\end{tabular}

Band gap is another interesting property of a polymer. Unfortunately, frontier orbital energy difference obtained through SCF calculations is not a particularly reliable measure of this quantity. If no orbital degeneracy is involved, a reasonable estimate of the optical gap $\left(\mathrm{S}_{1}-\mathrm{S}_{0}\right)$ can be obtained through limited configuration interaction, such as single and pair excitations spanning a space of 18 frontier orbitals. Although this procedure does not quantitatively yield the experimentally measured band gaps, the trends are often nicely reproduced.

\section{Results and discussion}

\section{Structure, bonding and energetics}

The optimized geometries (HF/3-21G) of $\mathbf{1 a}$ and $\mathbf{1 b}$ as well as the corresponding $C_{2 v}$ structures, $1 \mathbf{a r}$ and $\mathbf{1 b r}$, obtained by twisting one of the phenyl units by $90^{\circ}$ are shown in Figures 2 and 3, respectively. Heats of formation $\left(\mathrm{kcal} \mathrm{mol}^{-1}\right)$ and total energies (negative Hartree) as well as relative energies ( $\mathrm{kcal} \mathrm{mol}^{-1}$ ) of all the systems considered are given in Table 1 .

The heats of formations were calculated at semiempirical levels to be in the range 242.2 to $269.8 \mathrm{kcal} \mathrm{mol}^{-1}$ for the structures considered. Since a single $\mathrm{C}_{6} \mathrm{H}_{4}$ unit in linear polyparaphenylene is estimated to contribute only $30.9 \mathrm{kcal} \mathrm{mol}^{-1}$ (MNDO) [21,23], the computed values indicate the substantial amount of strain in $\mathbf{1 a}$ and $\mathbf{1 b}$. In the preferred geometry, the strain energy per $\mathrm{C}_{6} \mathrm{H}_{4}$ unit is estimated to be $18.0 \mathrm{kcal}$ $\mathrm{mol}^{-1}$ for 1a, but drops to $12.1 \mathrm{kcal} \mathrm{mol}^{-1}$ for the larger cycle 1b. The symmetric belt-like structures with $D_{5 h}$ and $D_{6 h}$ symmetry are calculated to be the most stable conformers at both semiempirical levels. For $\left[0_{6}\right]$ paracyclophane, the barrier for rotation of a single phenyl ring is computed to be 9.5 and $17.1 \mathrm{kcal} \mathrm{mol}^{-1}$ using MNDO and AM1 methods, respectively. The barrier is calculated to be higher for the smaller analog
Scheme 2 Optimized geometries of $\left[0_{5}\right]$ - and $\left[0_{6}\right]$ paracyclophanes (1a and $\mathbf{1 b})$, with the three unique $C$ - $C$ bond lengths in $\AA$ and angle of puckering of the six-membered rings in degrees
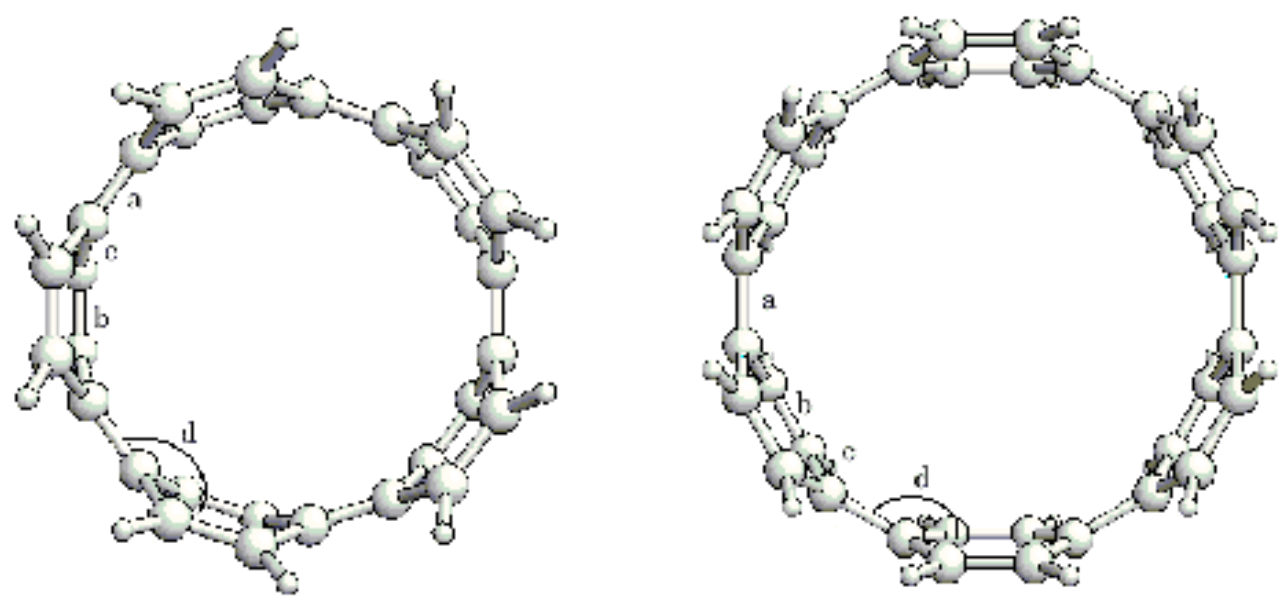

\begin{tabular}{|lr|l|c|}
\hline & AM1 & MNDO & HF/3-21G \\
\hline $\mathrm{a}=$ & 1.36 & 1.37 & 1.34 \\
$\mathrm{~b}=$ & 1.35 & 1.36 & 1.36 \\
$\mathrm{c}=$ & 1.46 & 1.48 & 1.48 \\
$\mathrm{~d}=$ & 152.8 & 151.1 & 154.8 \\
\hline
\end{tabular}

\begin{tabular}{|lr|c|c|}
\hline & AM1 & MNDO & HF/3-21G \\
\hline $\mathrm{a}=$ & 1.46 & 1.48 & 1.51 \\
$\mathrm{~b}=$ & 1.39 & 1.40 & 1.38 \\
$\mathrm{c}=$ & 1.41 & 1.42 & 1.39 \\
$\mathrm{~d}=$ & 164.5 & 162.4 & 167.5 \\
\hline
\end{tabular}


Scheme 3 Optimized geometries of $\mathrm{C}_{2 \mathrm{v}}$ isomers of $\left[\mathrm{O}_{5}\right]$ and $\left[0_{6}\right]$ paracyclophanes (1ar and $1 \mathrm{br}$ ), with the unique $C$ - $C$ bond lengths in $\AA$ and angle of puckering of the sixmembered rings in degrees
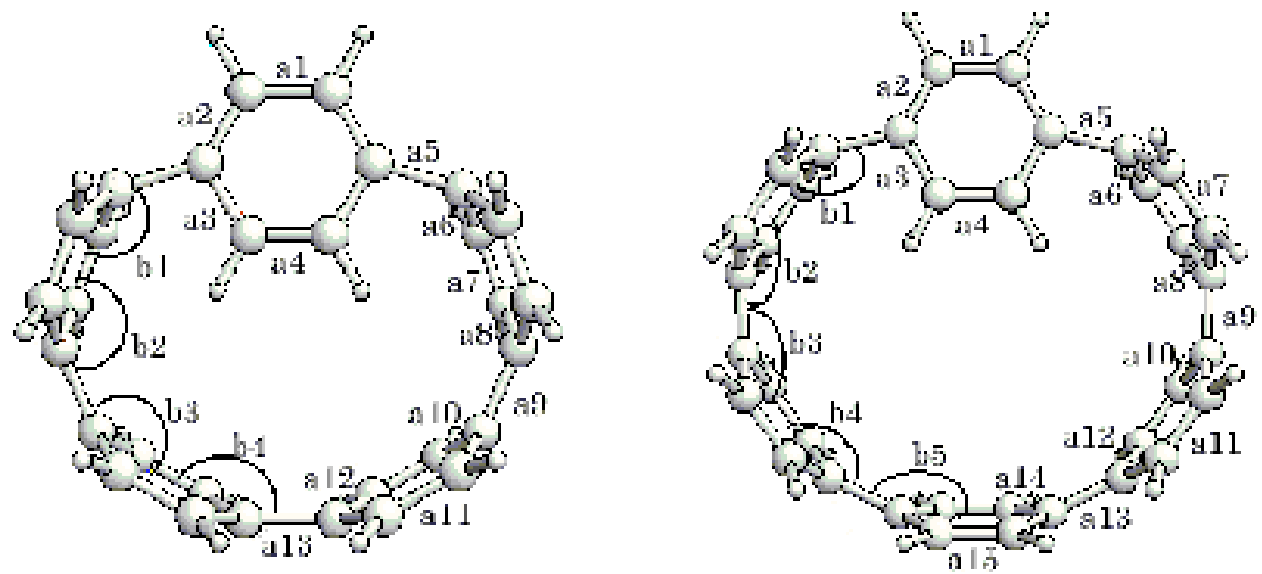

\begin{tabular}{|ll|l|l|}
\hline & AM1 & MNDO & $\begin{array}{l}\text { HF/3 } \\
21 G\end{array}$ \\
\hline $\mathrm{a} 1=$ & 1.42 & 1.44 & 1.42 \\
$\mathrm{a} 2=$ & 1.38 & 1.40 & 1.38 \\
$\mathrm{a} 3=$ & 1.42 & 1.43 & 1.40 \\
$\mathrm{a} 4=$ & 1.36 & 1.37 & 1.35 \\
$\mathrm{a} 5=$ & 1.48 & 1.49 & 1.53 \\
$\mathrm{a} 6=$ & 1.41 & 1.43 & 1.39 \\
$\mathrm{a} 7=$ & 1.39 & 1.40 & 1.38 \\
$\mathrm{a} 8=$ & 1.41 & 1.43 & 1.40 \\
$\mathrm{a} 9=$ & 1.46 & 1.48 & 1.52 \\
$\mathrm{a} 10=$ & 1.41 & 1.43 & 1.40 \\
$\mathrm{a} 11=$ & 1.39 & 1.40 & 1.38 \\
$\mathrm{a} 12=$ & 1.41 & 1.43 & 1.40 \\
$\mathrm{a} 13=$ & 1.46 & 1.48 & 1.51 \\
$\mathrm{~b} 1=$ & 156.2 & 153.6 & 162.8 \\
$\mathrm{~b} 2=$ & 155.4 & 152.3 & 161.0 \\
$\mathrm{~b} 3=$ & 163.5 & 161.1 & 166.3 \\
$\mathrm{~b} 4=$ & 164.1 & 162.4 & 166.8 \\
& & & \\
& & & \\
& & & \\
\hline
\end{tabular}

\begin{tabular}{|c|c|c|c|}
\hline & AM1 & MNDO & $\begin{array}{l}\mathrm{HF} / 3 \\
21 \mathrm{G}\end{array}$ \\
\hline $\mathrm{a} 1=$ & 1.41 & 1.43 & 1.41 \\
\hline $\mathrm{a} 2=$ & 1.39 & 1.40 & 1.38 \\
\hline$a^{3}=$ & 1.42 & 1.43 & 1.40 \\
\hline $\mathrm{a} 4=$ & 1.37 & 1.38 & 1.36 \\
\hline$a=$ & 1.47 & 1.49 & 1.52 \\
\hline$a 6=$ & 1.41 & 1.42 & 1.39 \\
\hline$a 7=$ & 1.39 & 1.40 & 1.38 \\
\hline$a 8=$ & 1.41 & 1.43 & 1.40 \\
\hline$a^{9}=$ & 1.46 & 1.48 & 1.51 \\
\hline $\mathrm{a} 10=$ & 1.41 & 1.42 & 1.39 \\
\hline $\mathrm{a} 11=$ & 1.39 & 1.40 & 1.38 \\
\hline $\mathrm{a} 12=$ & 1.41 & 1.42 & 1.39 \\
\hline $\mathrm{a} 13=$ & 1.46 & 1.48 & 1.51 \\
\hline a14 = & 1.41 & 1.42 & 1.39 \\
\hline a15 = & 1.39 & 1.40 & 1.38 \\
\hline $\mathrm{b} 1=$ & 161.0 & 158.3 & 166.6 \\
\hline $\mathrm{b} 2=$ & 159.7 & 156.5 & 164.8 \\
\hline $\mathrm{b} 3=$ & 164.2 & 161.6 & 167.1 \\
\hline $\mathrm{b} 4=$ & 164.7 & 162.5 & 167.5 \\
\hline $\mathrm{b} 5=$ & 166.4 & 165.3 & 169.0 \\
\hline
\end{tabular}

$\left[0_{5}\right]$ paracyclophane at the MNDO level $\left(25.1 \mathrm{kcal} \mathrm{mol}^{-1}\right)$, but lower $\left(6.0 \mathrm{kcal} \mathrm{mol}^{-1}\right)$ at the AM1 level.

The conformational preference obtained at higher level theory for 1a is opposite to that obtained with the semiempirical methods. The preferred structure corresponds to the $C_{2 v}$ form with one phenyl ring twisted out of conjugation with the rest of the belt. While the energy difference is fairly small at the HF/6-31G* level, a clear preference for the $C_{2 v}$ structure is obtained at both the HF/3-21G level and the more reliable B3LYP/6-31G* level, which includes a fair amount of dynamical correlation effects. The higher level theoretical results for $\left[0_{6}\right]$ paracyclophane $\mathbf{1 b}$ are however similar to those obtained using semiempirical methods. The $D_{6 h}$ isomer is calculated to be preferred and the barrier is computed to be in the range 9.5 to $16.9 \mathrm{kcal} \mathrm{mol}^{-1}$.

The computed structures provide some clues about the variations in computed energy differences. The optimized geometric parameters are fairly similar for all the structures at both semiempirical and $a b$ initio levels. The length of bond ' $a$ ' connecting the phenyl rings (see Scheme 2) is quite short $(1.34 \AA)$ in the case of $\mathbf{1 a}$, indicative of a double bond. On the other hand, the corresponding length in the case of $\mathbf{1 b}$ is $1.51 \AA$, resembling a single bond. The other bonds of the hexagon units in the case of $\mathbf{1 b}$ are partial double bonds $(\mathrm{b}=$ 1.38; $c=1.39 \AA$ ). In marked contrast, for $\mathbf{1 a}$ ' $b$ ' is a double bond (1.36 $\AA$ ) and 'c' is a single bond (1.48 $\AA$ ). Thus, the $D_{5 h}$ 
structure 1a is essentially a quinonoid form, while the $D_{6 h}$ structure $\mathbf{1 b}$ is benzenoid in character. Thus, the six-membered rings are presumably nonaromatic in the case of 1a, but aromatic in $\mathbf{1 b}$.

The hexagonal rings are not flat in both $\mathbf{1 a}$ and $\mathbf{1 b}$. The rings are puckered to different extents. How much bending can a benzene ring withstand without giving up its aromatic character? This question has been keenly debated using various [n]paracyclophanes, 7 (a benzene ring connected at the para positions by $\mathrm{n}$ methylene units), as models. Both experiment [24] and theory [25] reveal that bond alternations are fairly small despite angle deformations as much as $30^{\circ}$. However, $a b$ initio calculations reveal a large reduction in resonance energy as a result of bending [25]. Interestingly, the bond lengths are predicted to respond strongly to the extent of bending in $\left[0_{5}\right]$ paracyclophane, in contrast to the effect seen in [n]paracyclophanes $(\mathrm{n}>3)$. In the $D_{5 h}$ structure, 1a, the six-membered units are bent from planarity by about $25-30^{\circ}$. The optimized bond parameters suggest that the rings are quinoidal and hence non-aromatic. The strong deformation of the benzene rings diminishes the overlap of $\pi$-orbitals, resulting in non-aromatic units. In the case the $D_{6 h}$ structure $\mathbf{1 b}$ also, the phenyl moieties are deformed from planarity by about $12.5-17.5^{\circ}$. But the bond lengths are comparable to values found in aromatic systems. Thus, in $\mathbf{1 b}$, the deformation of six-membered rings to the boat conformation does not preclude aromaticity of the rings.

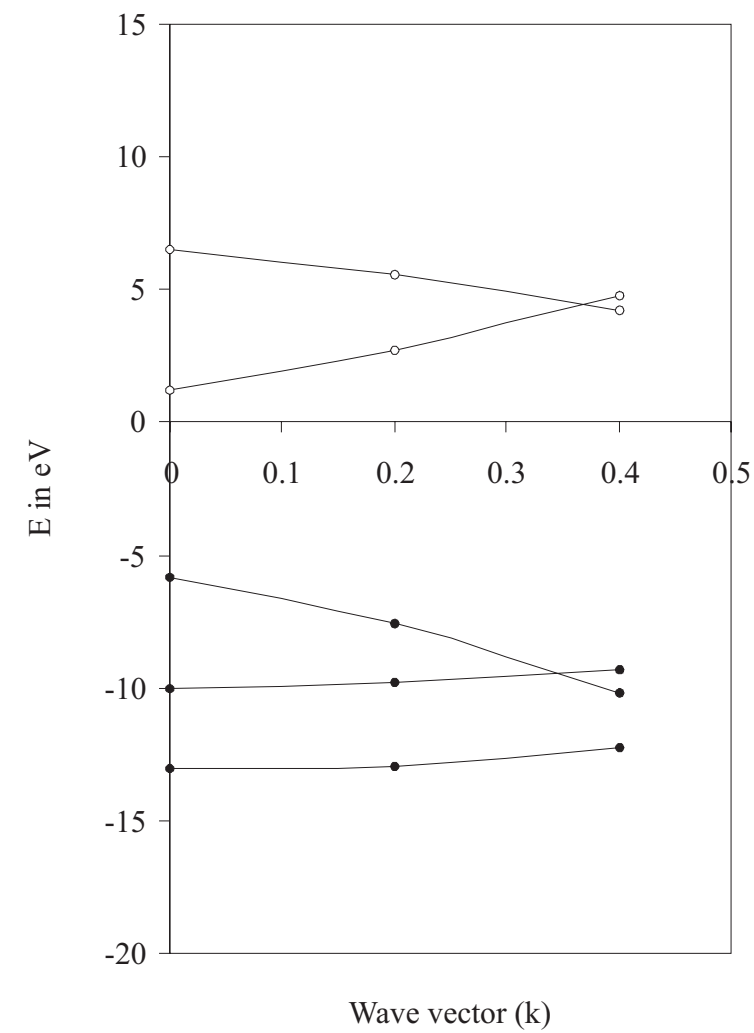

The fundamental difference in the electronic structures of 1a and 1b has several interesting consequences. The variations in strain and aromaticity associated with connected chains of quinonoid rings in $\mathbf{1 a}$ are not reproduced equally well at the various theoretical levels employed. The problem is less severe in the case of the higher analog $\mathbf{1 b}$. Another important result concerns the bond length variations in the conformers in which one phenyl ring is twisted out of conjugation. In the $C_{2 v}$ structures (Scheme 3), the six-membered units are benzenoid. While this is expected for $\mathbf{1 b r}$, the benzenoid character of the six-membered rings of 1ar indicates substantial bond reorganization accompanying the ring rotation. Interestingly, the six-membered rings of 1ar are puckered to a lesser extent by around $14-17^{\circ}$ compared to 1a, the $D_{5 h}$ isomer. Thus, $\mathbf{1 a r}$ is calculated to be more stable at all the higher levels of theory. The six-membered units gain aromatic character compared to the $D_{5 h}$ isomer 1a. A similar trend is observed for the rotational isomer $\mathbf{1 b r}$ also. The phenyl moieties of $\mathbf{1 b r}$ are benzenoid and the rings are puckered to a smaller extent $\left(11^{\circ}\right.$ to $\left.13^{\circ}\right)$ than in the $D_{6 h}$ form.

The computed NICS values at the center of the structures $\mathbf{1 a}$ and $\mathbf{1 b}$ confirm the above interpretations, based primarily on bond length variations. Both the structures are indicated to be overall non-aromatic, with small NICS values of $0.6 \delta$ and $-3.3 \delta$ at the center of the belt. There is relatively less extended conjugation around the belt. The NICS at the center of each phenyl unit confirms the difference in the aromatic

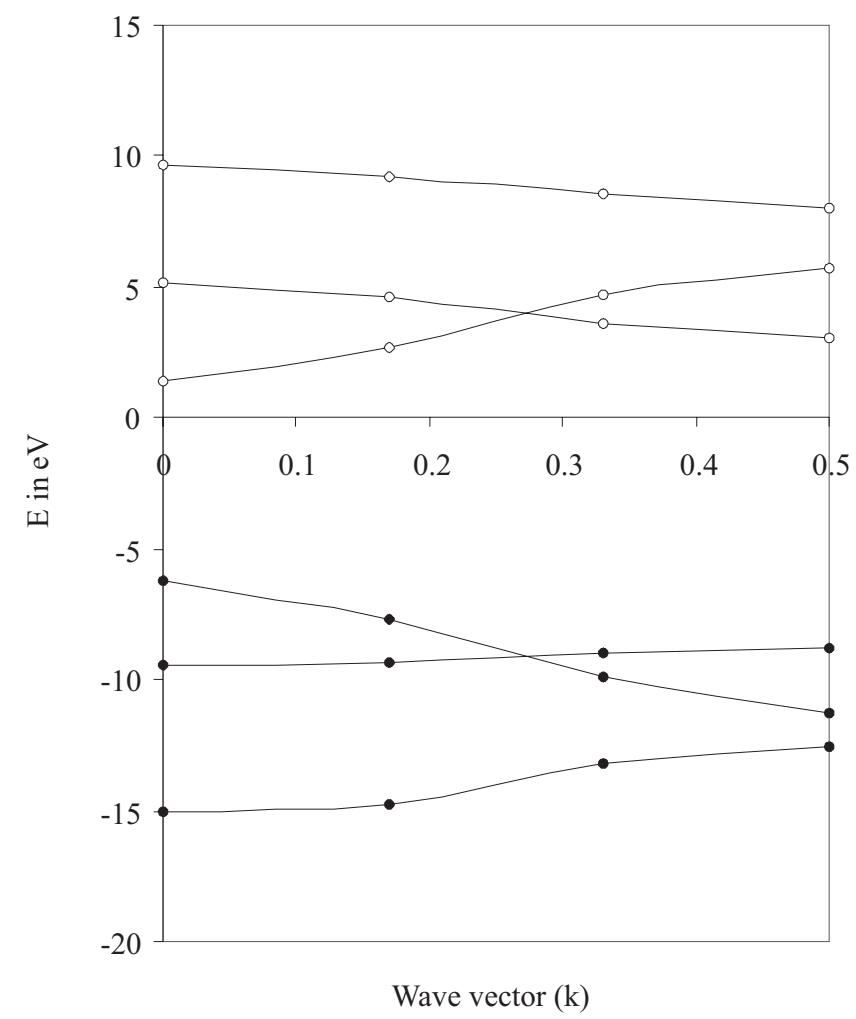

Figure 2 Band structures of [0n]paracyclophane with (a) quinonoid and (b) benzenoid structures 
character of the six-membered rings in $\mathbf{1 a}$ and $\mathbf{1 b}$. The values are $-0.1 \delta$ and $9.2 \delta$, respectively, implying that the rings of $\mathbf{1 a}$ are non-aromatic while the phenyl subunits of $\mathbf{1 b}$ are aromatic.

It is interesting to contrast the nature of bonding in the free belt 1a with that of the pentaphenyl belt in $\mathrm{C}_{70}$. In the fullerene system, the equatorial belt has considerable benzenoid character. This is reflected in the bond lengths, which fall in the aromatic range, and in the ability to undergo addition to bonds which are formally part of a pentagon [11]. Evidently, the additional connectivity along both the polar axes, especially to pentagons, as well as curvature in these directions alter the intrinsic preference for a quinonoid structure of a pentaphenyl unit. Larger $\left[0_{n}\right]$ paracyclophane units found in nanotubes should retain the benzenoid character predicted for the isolated molecular entity.

\section{Band structures}

The approximate band structures for an infinite polymer $\left[0_{n}\right]$ paracyclophane with quinonoid structure as well as with benzenoid structure were obtained at AM1 and the $a b$ initio $\mathrm{HF} / 3-21 \mathrm{G}$ levels from the oligomer orbital energies of $\mathbf{1 a}$ and $\mathbf{1 b}$. The $\mathrm{k}$ values were assigned to all $\pi$ and $\pi^{*}$ molecular orbitals of the individual hexagonal units. The band structures at the two theoretical levels are quite similar. The $a b$ initio data are shown in Figure 2.

The band structures can be understood from the nature of nodes in the various $\pi$ molecular orbitals (Figure 3 ). The variations in each band are almost the same irrespective of the method used for obtaining the band structure. The lowest band derived from combinations of the lowest energy $\pi \mathrm{MO}$ of benzene smoothly increases in energy with increasing $\mathbf{k}$. This is understandable since the interactions between adjacent fragment orbitals become increasingly less favorable as the phase changes occur more frequently (Figure 3a). A different behavior is seen for the next set of bands. One of the doubly degenerate MO's has a node going through the translation axis (Figure 3b). Hence, relatively little interaction along the cycle is possible. The corresponding band is extremely narrow. The other component of the degenerate filled orbital of a six-membered ring has large coefficients on the connecting atoms of the $\mathrm{C}_{6} \mathrm{H}_{4}$ units (Figure $3 \mathrm{c}$ ). This results in strong interaction along the chain, resulting in a well spread out band. Since this orbital has opposite phases on either connecting end, arranging the orbitals without introducing any sign change leads to maximum destabilization. Hence, the corresponding band has the highest energy at $\mathbf{k}=0$. The shapes of the bands resulting from the unoccupied orbitals can be similarly rationalized.

The computed optical gap of $\mathbf{1 b}$ is calculated to be as low as $1.8 \mathrm{eV}$ (PECI = 18). For 1a, a marginally higher optical gap of $2.5 \mathrm{eV}$ is obtained. Both these values suggest that the infinite polymer may well be an organic semiconductor [21]. Of course, the results correspond to an isolated infinite belt and the effects of intermolecular interactions have not been taken into account.

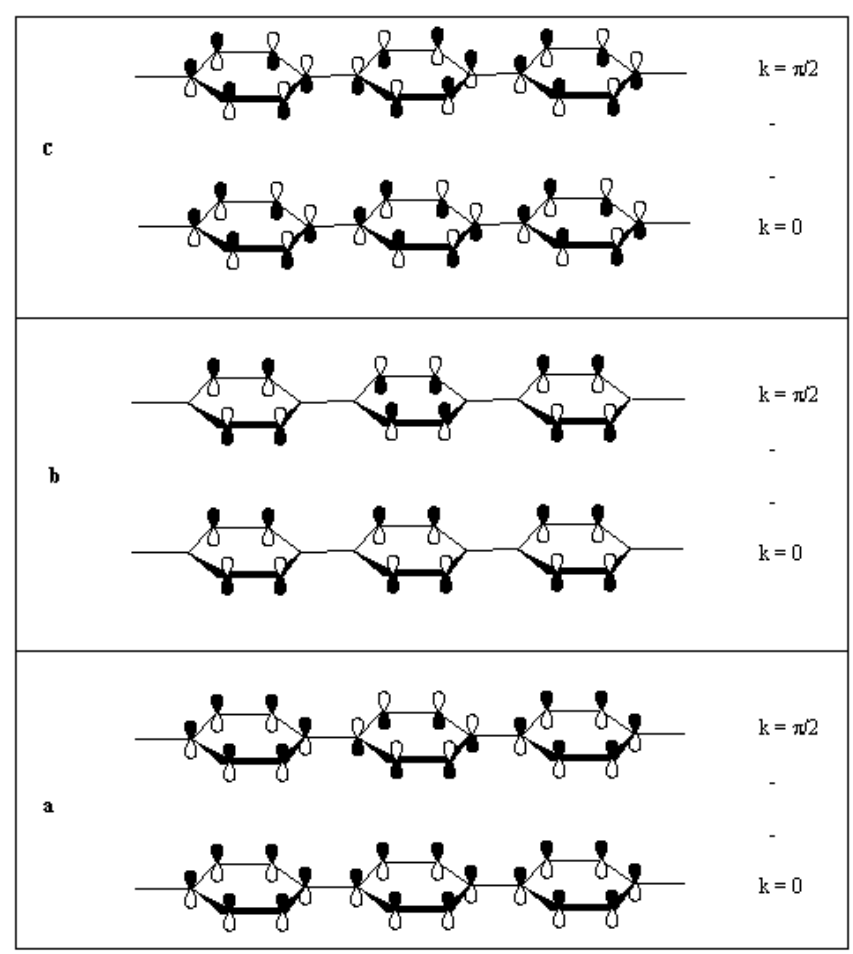

Figure 3 Schematic representation of the variation of the $\pi$ orbital energies (corresponding to $k=0$ and $k=\pi / 2$ ) of $\mathrm{C}_{6} \mathrm{H}_{4}$ units of $\left[\mathrm{O}_{n}\right]$ paracyclophanes. The band derived from the lowest $\pi M O$ of the benzene ring is shown in (a). The bands derived formally from the two degenerate highest occupied MOs of benzene are shown in (b) and (c)

\section{Conclusions}

The electronic structures of $\left[0_{5}\right]-$ and $\left[0_{6}\right]$ paracyclophanes are fundamentally different. The smaller pentaphenylene is predicted to have a quinonoid structure, presumably to reduce the overall strain the system. In contrast, the hexagons in cyclic hexaphenylene have benzenoid character. The differences are reflected in the computed barriers to rotation of a single phenyl unit as well as in the NICS values of individual rings. Approximate band structure calculations indicate that $\left[0_{n}\right]$ paracyclophanes have relatively small band gaps and hence may behave like organic semiconductors.

Supplementary material available $\mathrm{HF} / 3-21 \mathrm{G}$ optimized geometries of $\mathbf{1 a}, \mathbf{1 a r}, \mathbf{1 b}$ and $\mathbf{1 b r}$ in pdb format.

\section{References and notes}

1. (a) Kroto, H. W.; Heath, J. R.; O’Brien, S. C.; Curl, R. F.; Smalley, R. E. Nature 1985, 318, 162. (b) Kroto, H. W. Angew. Chem., Int. Ed. Engl. 1992, 31, 111.

2. (a) Iijima, S Nature 1991, 354, 56. (b) Ruoff, R. S. Nature 1994, 362, 731. 
3. (a) Baldridge, K. K.; Siegel, J. S. J. Am. Chem. Soc. 1999 121, 5332. (b) Chandrasekhar, J. J. Ind. Inst. Sci. 1996, 76, 487. (c) Chandrasekhar, J. Current Science 1993, 65, 595.

4. (a) Mehta, G.; Prakash Rao, H. S. Tetrahedron 1998, 54, 13325. (b) Rubin, Y. Chem. Eur. J. 1997, 3, 1009.

5. (a) Vögtle, F. Top. Curr. Chem. 1983, 115, 157. (b) Friederich, R.; Nieger, M.; Vögtle, F. Chem. Ber. 1993, 126, 1723.

6. Kawabe, T.; Darabi, H. R.; Oda, M. Angew. Chem., Intl. Ed. Engl. 1996, 35, 2664.

7. (a) Ashton, P. R.; Brown, R. G.; Isaacs, N. S.; Giuffrida, D.; Kohnke, F. H.; Mathias, J. P.; Stawin, A. M. Z.; Smith, D. R.; Stoddart, J. F.; Williams, D. J. J. Am. Chem. Soc. 1992, 114, 633. (b) Graham, R. J.; Paquette, L. A. J. Org. Chem. 1995, 60, 5770. (c) Cory, R. M.; McPhail, C. L.; Dikmans, A. J.; Vittal, J. J. Tetrahedron Lett. 1996, 37, 1983. (d) Cory, R. M.; McPhail, C. L. Tetrahedron Lett. 1996, 37, 1987.

8. (a) Wiberg, K. B.; Matturro, M.; Adams, R. J. Am. Chem. Soc. 1981, 103, 1600. (b) McMurry, J. E.; Haley, G. J.; Matz, J. R.; Clardy, J. C.; van Duyne, G. J. J. Am. Chem. Soc. 1984, 106, 5018. (c) McMurry, J. E.; Haley, G. J.; Matz, J. R.; Clardy, J. C.; Mitchell, J. J. Am. Chem. Soc. 1986, 108, 515. (d) Rubin, Y.; Knobler, C. B.; Diederich, F. J. Am. Chem. Soc. 1990, 112, 4966. (e) Diederich, F.; Rubin, Y. Angew. Chem., Int. Ed. Engl. 1992, 31, 1101. (f) Tobe, Y.; Lalii, T.; Matsumoto, H.; Naemura, K.; Achiba, Y.; Wakabayashi, T. J. Am. Chem. Soc. 1996, 118, 2758. (g) Tobe, Y.; Matsumoto, H.; Naemura, K.; Achiba, Y.; Wakabayashi, T. Angew. Chem., Int. Ed. Engl. 1996, 35,1800

9. (a) Despress, J. K.; Daguerre, E.; Lafdi, K. Carbon 1995, 33, 87. (b) Heer, W. A.; Bacsa, W. S.; Chatelain, A.; Geftin, T.; Humphrey-Baker, R.; Forro, L.; Ugarte, D. Science 1995, 268, 846 .

10. (a) Faust, R. Angew. Chem., Int. Ed. Engl. 1995, 34, 1429. (b) Scott, L. T. Pure Appl. Chem. 1996, 68, 291.

11. (a) Govindaraj, A.; Rathna, A.; Chandrasekhar, J.; Rao, C. N. R. Proc. Indian Acad. Sci. (Chem. Sci.) 1993, 105, 303. (b) Rathna, A.; Chandrasekhar, J. Current Science 1993, 65, 768. (c) Weedon, B. R.; Haddon, R. C.; Spielmann, H. P.; Meier, M. S. J. Am. Chem. Soc. 1999, $121,335$.

12. Hirsch, A. Chemistry of the Fullerenes; Thieme Verlag: Stuttgart, 1994.

13. Parekh, V. C.; Guha, P. C. J. Indian Chem. Soc. 1934, 11, 95.

14. Tsuji, T.; Okuyama, M.; Ohkita, M.; Imai, T.; Suzuki, T. J. Chem. Soc., Chem. Commun. 1997, 2151.

15. Viavattene, R. L; Greene, F. D.; Cheung, L. D.; Majeste, R.; Trefonas, L. M. J. Am. Chem. Soc. 1974, 96, 4342.

16. (a) Kammermeier, S.; Herges, R. Angew. Chem., Int. Ed. Engl. 1996, 35, 417. (b) Kammermeier, S.; Jones, P. G.; Herges, R. Angew. Chem., Int. Ed. Engl. 1996, 35, 2669. (c) Kammermeier, S.; Jones, P. G.; Herges, R. Angew. Chem., Int. Ed. Engl. 1997, 36, 2200.
17. (a) Dewar, M. J. S.; Thiel, W. J. Am. Chem. Soc. 1977, 99, 4899, 4907. (b) Dewar, M. J. S.; Healy, E. F.; Stewart, J. J. P.; Zoebisch, E. G. J. Am. Chem. Soc. 1985, 107, 3902.

18. (a) Hehre, W. J.; Radom, L.; Schleyer, P. v. R.; Pople, J. A. Ab Initio Molecular Orbital Theory, Wiley \& Sons: New York, 1986. (b) Ab initio calculations were carried out using the Gaussian 94 suite of programs: Frisch, M. J.; Trucks, H. B.; Schlegel, H. B.; Gill, P. M. W.; Johnson, B. G.; Robb, M.A.; Cheeseman, J. R.; Keith, T.; Petersson, G. A.; Montgomery, J. A.; Raghavachari, K.; Al-Laham, M. A.; Zakrzewski, V. G.; Ortiz, J. V.; Foresman, J. B.; Cioslowski, J.; Stefanov, B. B.; Nanayakkara, A.; Challacombe, M.; Peng, C. Y.; Ayala, P. Y.; Chen, W.; Wong, M. W.; Andres, J. L.; Replogle, E. S.; Gomperts, R.; Martin, R. L.; Fox, D. J.; Binkley, J. S.; Defrees, D. J.; Baker, J.; Stewart, J. J. P.; Head-Gordon, M.; Gonzalez, C.; Pople, J. A. Gaussian Inc., Pittsburgh, PA, 1995.

19. (a) Becke, A. D. J. Chem. Phys. 1993, 98, 5648. (b) Lee, C.; Yang, W.; Parr, R. G. Phys. Rev. B 1988, 37, 785.

20. (a) Schleyer, P. v. R.; Maerker, C.; Dransfeld, A.; Jiao, H.; van Eikema Hommes, N. J. R. J. Am. Chem. Soc. 1996, 118, 6317. (b) Jiao, H.; Schleyer, P. v. R. Angew. Chem., Int. Ed. Engl. 1996, 35, 2383. (c) Subramanian, G.; Schleyer, P. v. R.; Jiao, H. Angew. Chem., Int. Ed. Engl. 1996, 35, 2638. (d) Unverzagt, M.; Winkler, H. J.; Brock, M.; Hofmann, M.; Schleyer, P. v. R.; Massa, W.; Berndt, A. Angew. Chem., Int. Ed. Engl. 1997, 36, 853.

21. Chandrasekhar, J.; Das, P. K. J. Phys. Chem. 1992, 96, 679.

22. (a) Hoffmann, R. Angew. Chem., Int. Ed. Engl. 1987, 29, 871. (b) Baetzold, R. C.; Hamilton, J. F. Prog. Solid State Chem. 1984, 15, 1. (c) Cioslowski, J.; Kertesz, M. J. Chem. Phys. 1988, 85, 7193.

23. Cui, C. X.; Kertesz, M.; Jiang, Y. J. Phys. Chem. 1990, 94, 5172 .

24. (a) Jenneskens, C. W.; de Kanter, F. J. J.; Kraakman, P. A.; Tinkenburg, L. A.; Koolhaas, W. E.; de Wolf, W. H.; Bickelhaupt, F.; Tobe, Y.; Kakiuchi, K.; Odaira, Y. J. Am. Chem. Soc. 1985, 107, 3716. (b) Tobe, Y. Top. Curr. Chem. 1994, 172, 1. (c) Kane, V. V.; Wolf, A. D.; Jones, M., Jr. J. Am. Chem. Soc. 1974, 96, 2643. (d) Cram, D. J.; Cram, J. M. Acc. Chem. Res. 1971, 4, 204.

25. (a) Dijkstra, F.; van Lenthe, J. H. Int. J. Quantum Chem. 1999, 74, 213. (b) Ma, B. Y.; Sulzbach, H. M.; Remington, R. B.; Schaefer, H. F. J. Am. Chem. Soc. 1995, 117, 8392. (c) Frank, I.; Grimme, S.; Peyerimhoff, S. D. J. Am. Chem. Soc. 1994, 116, 5949. (d) Grimme, S. J. Am. Chem. Soc. 1992, 114, 10542. (e) Lee, J. T.; Rice, J. E.; Remington, R. B.; Schaefer III, H. F. Chem. Phys. Lett. 1988, 150, 63. (f) Lee, J. T.; Rice, J. E.; Remington, R. B.; Schaefer III, H. F. Chem. Phys. 1988, 123, 1. (g) Rice, J. E.; Lee, T. J.; Remington, R. B.; Allen, W. D.; Clabo, D. A.; Schaefer III, H. F. J. Am. Chem. Soc. 1987, 109, 2902. (h) Remington, R. B.; Lee, T. J.; Schaefer III, H. F. Chem. Phys. Lett. 1986, 124, 199. 